\title{
Knowledge management in forensic accounting: the future trends
}

\begin{abstract}
Nowadays, Information System (IS) plays major roles in organizations to support the business processes, decision making and provide support on competitive advantage strategies for the employees and managers. These functions are significant since the business processes become more diverse and involve a large amount of transactions. Due to the diversity of the business process, information safekeeping on financial records is very crucial for managing the organizations knowledge. Thus, financial crime is not as visible as conventional crime hence detection is usually difficult. It is basically the work of the Auditors or Investigators to carefully process the information gathered from a company's database to an evidence to be presented at the law court while investigating the financial crime. This paper covers related study on the usage of information technology in supporting and facilitating financial crime investigation in order to produce substantial evidence suitable for use in the law court. The study and directions for future research on knowledge management in forensic accounting also included in the paper.
\end{abstract}

Keyword: Forensic accounting; Fraud; Information Systems; Knowledge management 